\title{
BREVE ENSAIO SOBRE AS NECESSIDADES HUMANAS BÁSICAS, O DIREITO À SAÚDE E A AUTONOMIA DOS DOENTES MENTAIS
}

\author{
Brief essay about human needs, the right to health and autonomy of the mentally \\ ill
}

Ana Raquel Santiago de Lima (UFS) Ana Maria Fernandes Pitta (UCSal)

Informações do artigo

Recebido em 23/06/2018

Aceito em 17/02/2019

doi>: https://doi.org/10.25247/2447-861X.2019.n246.p15-27

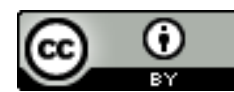

Esta obra está licenciada com uma Licença Creative Commons Atribuição 4.0 Internacional.

Como ser citado (modelo ABNT)

LIMA, Ana Raquel Santiago de; PITTA, Ana Maria Fernandes. Breve ensaio sobre as necessidades humanas básicas, o direito à saúde e a autonomia dos doentes mentais. Cadernos do CEAS: Revista Crítica de Humanidades, Salvador, n. 246, jan./abr., p. 15-27, 2019. DOI: https://doi.org/10.25247/2447861X.2019.n246.p15-27

\begin{abstract}
Resumo
Este artigo, escrito em forma de ensaio, considera como necessidades básicas humanas as condições universais para a participação social. Essas condições são a saúde e a autonomia crítica. Pretende percorrer os conceitos de necessidades básicas, direito à saúde e autonomia, adentrando à área de saúde mental, a fim de discorrer sobre como foram tratados os doentes mentais e como seus direitos à saúde e à liberdade foram sequestrados em nome do saber científico e médico. Ressalta, ainda, as formas de alienação na sociedade contemporânea, a passagem do poder por submissão dos corpos para "poder inteligente" - que submete através da dominação por excesso de liberdade - sendo essa a evolução do poder neoliberal, e a liberdade fantástica que aprisiona mentes e desejos, o fomento de novas necessidades. Conclui apontando para a necessidade do respeito à singularidade dos doentes mentais e para a importância de políticas sociais intersetoriais que transcendam o campo da saúde, entendendo-a num conceito mais amplo, para além da ausência de doenças.
\end{abstract}

Palavras-chave: Necessidades humanas. Saúde mental. Neoliberalismo.

\section{Abstract}

This article written in essay form considers the basic human needs the universal conditions for social participation. These conditions are health and critical autonomy. It intends to go through the concepts of basic needs, the right to health and autonomy, entering the area of mental health in order to discuss how the mentally ill were treated and how their rights to health and freedom were abducted in the name of medical and scientific knowledge. It also emphasizes the forms of alienation in contemporary society, the transition from power by submission of bodies to "intelligent power" that it subjects through domination by excess of freedom, which is the evolution of neoliberal system. It concludes by pointing to the need for respect the uniqueness of the mentally ill and to the importance of intersectorial social policies that transcend the field of health by understanding it in a broader concept beyond the absence of disease.

Keywords: Human needs. Mental health. Neoliberalism. 


\section{Necessidades humanas básicas e o direito à saúde}

Para Wolkmer (2004), devemos elucidar o que realmente chamamos de necessidades humanas ou básicas. Dizem respeito, sobretudo, às necessidades existenciais, sociais e culturais.

A dinâmica das necessidades e das carências que permeia o indivíduo e a coletividade refere-se tanto a um processo de subjetividade, modos de vida, desejos e valores quanto a constante ausência ou vazio de algo almejado e nem sempre realizável. (WOLKMER, 2004, p. 86).

As necessidades são inesgotáveis e definidas também historicamente, sempre em processo de recriação devido às novas motivações. Os movimentos dos coletivos organizados ou não são os propulsores das demandas por novos direitos e novas necessidades. No entanto, este conceito de subjetividade das necessidades é controverso e não unanimidade.

Wolkmer (2004, p. 87) nos alerta que é na vivência da carência e da negação de direitos que são forjados os movimentos sociais. Para este autor "[...] o direito aparece aqui como fator articulador que internaliza a passagem da necessidade a reivindicação".

Nas sociedades capitalistas centrais, o clamor por liberdades individuais, participação popular e autonomia/igualdade econômica fomentou a luta e a conquista de direitos políticos e sociais.

Ainda temos muito a conquistar neste campo, pois vivemos num cenário de profunda desigualdade social, numa sociedade excludente, onde a luta é pela satisfação das necessidades para a sobrevivência: trabalho, moradia, saúde, alimentação, lazer, educação, repouso. Direitos já conquistados pela sociedade capitalista ocidental (WOLKMER, 2004).

Consideram-se necessidades básicas humanas as condições universais para a participação social. Essas condições são a saúde e a autonomia crítica. A primeira, pois sem ela não existimos enquanto seres humanos e a segunda a fim de que possamos "[...] conhecer, criticar e contribuir para a mudança do meio" (GOMES JÚNIOR; PEREIRA, 2013, p. 55).

Para Dallari (1988), o direito à saúde, quando observado como direito individual, tem a liberdade como a sua mais ampla acepção. Segue afirmando que ter direito à saúde diz 
respeito à liberdade de escolher o tipo de relação que se tem com a cidade onde moramos, com o meio ambiente, as escolhas que fazemos com relação às condições de trabalho, bem como quais recursos sanitários escolhemos procurar quando adoecidos e a quais tipo de tratamento nos submeteremos.

Porém a autora alerta que essa liberdade também se refere ao direito dos profissionais de saúde em escolherem submeter seus clientes ao tratamento que julgarem mais adequado. Sendo assim, conclui que "[...] a efetiva liberdade necessária ao direito à saúde enquanto direito subjetivo depende do grau de desenvolvimento do Estado" (DALLARI, 1988, p.59).

De fato, unicamente no Estado desenvolvido socioeconomicamente e culturalmente o indivíduo é livre para procurar um completo bem estar físico, mental e social e para, adoecendo, participar do estabelecimento do tratamento. (DALLARI, 1988, p. 59).

Em última análise, o que garantiria o direito à saúde é a organização do Estado em fomentar o acesso da população a esta necessidade básica e a participação popular na luta e regulação da garantia do mesmo.

\section{Sobrevoo sobre as necessidades na era da psicopolítica neoliberal}

Temos testemunhado, na atual sociedade capitalista, o público ceder espaço para o privado e o mercado inundando as mentes de ideias de competição e mérito. Han (2015) chama esse novo patamar de psicopolítica neoliberal, onde assistimos a dominação de mentes e desejos.

Assim, as necessidades "básicas" são as de consumo, são as necessidades do capital. O resultado disso é a incansável busca por satisfação pessoal em detrimento de ideias de coletividade, solidariedade e participação social.

Gomes Júnior e Pereira (2013, p. 6) afirmam que "[...] a vida online substitui a participação popular nas lutas, pela adesão subliminar, silenciosa". A noção de liberdade é capturada e substituída pela ideia de liberdade de consumo: cidadania se confunde com o poder de consumo.

O imaginário social globalizado substitui os signos de identidade, trocandoos por uma ideia difusa de pertencimento a partir de uma mesma igualdade a ser vivida por todos, em todos os lugares e espaços. Igualdade está que não leva em conta os efeitos das realidades sócias, econômicas, políticas, 
tratando-os como se estivessem escritos ou encenados num universo paralelo [...] A realização dos indivíduos como cidadãos plenos de direitos, autônomo, livre funde-se a condição prévia de consumidor de mercadorias. (GOMES JÚNIOR; PEREIRA, 2013, p. 61-62).

Para Meszaros:

A completa subordinação das necessidades humanas à reprodução de valor de troca - no interesse da autorrealização ampliada do capital - tem sido o traço marcante do sistema do capital desde o seu início. Isto contrasta do modo mais agudo possível com as práticas produtivas do mundo antigo. De fato, as mudanças trazidas pela consolidação do domínio do capital como sistema de controle que a tudo absorve constituíram uma reversão radical dos princípios orientadores que caracterizavam a produção na Antiguidade clássica. (MESZAROS, 2002, p. 606).

O capitalismo não somente pretende a dominação dos corpos através da rigidez dos processos produtivos, o poder é forte justamente porque domina em nível do que desejam as pessoas (FOUCAULT, 2007).

Esta passagem do poder por submissão dos corpos para "poder inteligente", que submete através da dominação por excesso de liberdade, seria a evolução do poder neoliberal que utiliza não mais a disciplina para explorar, mas sim, o abuso da liberdade para coerção na busca de resultados autorreguláveis. (HAN, 2014; BAUMAN, 2007).

Nesse entendimento, HAN (2015) afirma que a depressão seria a expressão do fracasso do homem pós-moderno em dar conta do que se espera dele: ganhos de lucratividade, liquidez, resultados, eficiência e positividade ilimitados. Acrescenta que as doenças mentais, em especial a citada, derivam também das relações efêmeras, atomização do social e carência de profundidade. O que nos adoece e provoca infartos mentais não são os excessos de atividades e demandas, mas o imperativo do desempenho como "[...] mandato da sociedade pós-moderna do trabalho" (HAN, 2015, p. 27).

Os corpos continuam a ser explorados, dessa feita, na busca da otimização de neurônios através de livros de autoajuda e dos músculos pelos programas fitness (HAN, 2015). O culto ao belo e ao ótimo gera uma liberdade paradoxal e fantástica, uma vez que é justo esta condição que nos faz ser explorados.

Para Bauman "[...] a vida na sociedade líquida-moderna é a versão perniciosa da dança das cadeiras, jogada para valer. O verdadeiro prêmio nesta competição é a garantia 
(temporária) de ser excluído das fileiras dos destruídos e evitar ser jogado no lixo [...]" (BAUMAN, 2007, p.10).

\section{A alienação mental e a perda de liberdade}

Durante a época clássica, o hospício teve a função de hospedaria. Hospitais e casas de misericórdia abrigavam excluídos de todo gênero: prostitutas, leprosos, loucos, ladrões, vagabundos, todos que ameaçavam a ordem social. Neste período, ainda não havia a preocupação com critérios médicos e o que marca os loucos é a desrazão. A ética da época se organizou pelo primado da razão iluminista.

Já na idade média, século XVIII, há a convergência entre percepção, dedução e conhecimento e este internamente ganha símbolos médicos e características terapêuticas. Assim, a desrazão vai dando lugar à alienação enquanto critério de diferenciação do louco perante a ordem social. A doença mental torna-se objeto fundante da prática e do saber psiquiátrico.

No livro o "Nascimento da Clínica", Foucault (1977) descreve exatamente a transformação do hospital, inicialmente uma hospedaria, em uma instituição médica através da ação sistemática e dominante da disciplina, organização e investigação médica. A doença mental é definida como problema de ordem moral e fica instituído o tratamento moral (CASTEL, 1978).

A partir da segunda metade do Século XIX, a psiquiatria passa a ser o imperativo de ordenação dos sujeitos e assume uma matriz positivista, seguindo a orientação das ciências naturais. Limita-se a observar e descrever os fenômenos dos distúrbios nervosos. Até os dias atuais, observamos que este modelo nos influencia na medida em que é delegado ao psiquiatra o poder de definir se alguém pode ser levado, contra sua vontade, para um tratamento de exclusão social: única especialidade médica que tem esta prerrogativa.

Pinel escreveu seu "Tratado Médico-Filosófico sobre a Alienação Mental e a Mania" onde cunhou o conceito de alienação mental, que significava a desrazão ou um desvio ou contradição na razão lluminista. Esse desvio tornava os alienados incapazes de julgar, decidir e, por isso, incapazes de ser cidadãos livres (AMARANTE, 2009). 
Institui-se o isolamento social como método terapêutico para o tratamento da loucura visando ao tratamento moral, a fim de disciplinar os sujeitos para o retorno à vida social e à cidadania plena. Ao contrário dos cidadãos não alienados, estes estariam incapazes de decidir sobre o melhor tratamento a ser seguido.

A desrazão, ainda hoje, justifica sequestros de pessoas com transtornos mentais ou abuso de drogas para internações involuntárias e até mesmo compulsórias. Perde-se aí o direito à liberdade e à autonomia crítica.

Nem todo vulnerável perde sua autonomia crítica e também pessoas com autonomia reduzida podem não ser vulneráveis. Entendemos vulnerabilidade como uma condição resultante da relação social, cultural e política. A autonomia, por sua vez, é individual e sua redução pode ser uma condição transitória; no entanto, a redução ou o aumento da vulnerabilidade estão diretamente ligados à superação ou ao agravamento das consequências desta vulnerabilidade nos diversos âmbitos (social, econômico, político, etc).

\section{O Movimento Reformista e a luta pela garantia do direito ao cuidado em liberdade}

O movimento por mudanças na atenção à saúde mental no Brasil surge na década de 70, oriundo da insatisfação dos trabalhadores de hospícios brasileiros, pensadores e familiares de pacientes que sofriam e discordavam do andamento da política pública em saúde. Muitos psiquiatras e profissionais de saúde mental, à época, estiveram visitando a experiência de Triste e Gorizia na Itália, além de recebermos visitas e conferências de vários protagonistas de movimentos reformistas europeus.

A década de 90 aos anos 2000 foram marcados por avanços na força política deste movimento, que teve como resultado portarias federais e incentivos à reversão do modelo asilar para um modelo comunitário de atenção à saúde mental, consonante com as diretrizes internacionais (UZACÁTEOUI; LEVAV, 1991; CALDAS DE ALMEIDA; HORVITZ-LENNON, 2010; WHO, 2012; WHO 2013).

Apresentava-se como compromisso a reinserção psicossocial, a desestigmatização do doente mental, bem como a garantia do acesso aos serviços de saúde, inclusive à atenção primária sem preconceito e descriminação. 
O conceito e o termo reabilitação psicossocial passou a ser utilizado num contexto de desinstitucionalização e desinternação de pacientes de hospitais psiquiátricos no Brasil (SARACENO, 2001a).

Pitta (2001) compreende a reabilitação psicossocial como um processo que possibilita ao indivíduo, a despeito de suas limitações, maior autonomia na comunidade.

Já Saraceno (2001a) descreve a reabilitação psicossocial como um exercício de cidadania e contratualidade estabelecida em esferas diferentes e complementares como o morar, a rede de relações sociais e o trabalho. Para Kinoshita (2001), a reabilitação psicossocial seria um processo de restituição do poder contratual do usuário, visando ampliar sua autonomia.

O cenário da produção da sociedade tem o reconhecimento de um produto de valor social, ou seja, felizes ou não, todos querem um salário, e com ou sem reconhecimento, mudam de cenário e vão ao trabalho. A possibilidade de mudança está sempre presente [...] temos ai mais ou menos a medida da nossa capacidade contratual. Isto é, material de produção social, uns tem mais e outros têm menos. (SARACENO, 2001b. p. 15).

A reabilitação psicossocial é entendida como compromisso e necessidade ética para os trabalhadores da área de saúde mental. Não é uma tecnologia, é uma abordagem, uma estratégia "[...] que implica muito mais que simplesmente passar um usuário, um paciente, de um estado de desabilidade a um estado de habilidade, de um estado de incapacidade a um estado de capacidade" (SARACENO, 2001b).

Saraceno (2001a) critica severamente a psiquiatria enquanto assunção do papel de "entreter o paciente". Ele afirma que o psiquiatra distrai o paciente com suas técnicas e terapêuticas medicamentosas enquanto a doença mental segue seu curso, não necessariamente sendo influenciada pela terapêutica adotada.

Aponta que, na prática, percebe-se que outras variáveis influenciam no curso da doença mental em cada sujeito, não necessariamente a abordagem formal.

[...] os contextos onde o tratamento se dá1, as motivações e as expectativas de quem oferece o tratamento, os modos afetivos e materiais que constituem a assistência, a continuidade e a perspicácia com que são

\footnotetext{
${ }^{1}$ Se em serviços comunitários ou em instituições asilares.
} 
construídas propostas de vida para o paciente são mais decisivos para a evolução do mesmo. (SARACENO, 2001a, p. 17).

Esta discussão provoca reflexões que, talvez, não somente a terapêutica e a clínica seriam suficientes para gerar mudanças significativas nas vidas dos pacientes, e que nem somente de serotonina e conexões neuronais se faz uma existência de sofrimento psíquico e adoecimento mental.

A forma como é encarada a doença mental, seja pela pessoa com transtorno mental, seja pelos familiares e, ainda, pela sociedade, altera o curso da doença. Políticas sociais e de saúde que priorizem este viés de tratamento e abordagens psicossociais continuam sendo vanguarda neste campo.

\section{Estigma, direitos humanos e atenção à saúde mental}

O estigma corrói a possibilidade de contratualizar na sociedade: seja dentro da família, na rede social e na rede de saúde. Goffman (1988) nos fala que estigma tem a ver com identidade social mais do que com status social. Segue postulando que classificamos e categorizamos os indivíduos, quando estes nos são apresentados, baseando-nos em relações sociais para além dos atributos reais, "[...] podem surgir evidências de que ele tem um atributo que o torna diferente dos outros que se encontra em uma categoria que se pudesse ser incluído [...]" (GOFFMAN, 1988, p.12).

E complementa:

Assim, deixamos de considerá-lo criatura comum e total, reduzindo-o a uma pessoa estragada e diminuída. Tal característica é um estigma, especialmente quando o seu efeito de descrédito é muito grande - algumas vezes ele também é considerado um defeito, uma fraqueza, uma desvantagem - e constitui uma discrepância específica entre identidade social virtual e a identidade social real. (GOFFMAN, 1988, p.12).

As diretrizes mundiais seguem reafirmando a necessidade de que os países valorizem a saúde mental, promovam e protejam as pessoas com transtornos mentais, prevenindo agravos; que as pessoas já afetadas por doenças mentais possam exercer seus direitos civis e humanos no acesso aos serviços de saúde com qualidade e, no momento que mais precisem, através de serviços comunitários de saúde (WHO, 2013). 
O objetivo geral do Mental Health Action Plan 2013-2020 (WHO, 2013, p.9) é "[...] promover a saúde mental, prevenir transtornos mentais, prover tratamento (cuidado), enfatizar o restabelecimento dessas pessoas (recovery), promover os direitos humanos e reduzir a morbi-mortalidade para pessoas com doenças mentais".

Tais ações, em suma, buscam ampliar e fomentar o restabelecimento e a reconstrução de histórias de vida (recovery), mas também a redução da estigmatização e discriminação das pessoas com transtornos mentais, bem como garantir o atendimento de suas necessidades de saúde e autonomia.

Para que as pessoas com transtornos mentais possam se restabelecer, há a necessidade de fomento de serviços de saúde orientados para a reabilitação psicossocial que atuem de maneira intersetorial integrando educação, trabalho, assistência social e tantos outros setores que forem necessários à garantia de integralidade da atenção (PEREIRA, 2014).

O Estado não dá conta de cuidar das emergências sociais, também em crise assim como todo sistema, tem sua arrecadação e fontes de receitas reduzidas, pois não consegue regular o caos do mercado globalizado. Nas palavras de KURZ (1997, p. 104) "[...] passa então a endividar-se junto aos participantes do mercado financeiro".

Sentimos na pele o clima totalitário e de distopias em que vivemos. Onde não podemos ser diferentes e somos o tempo todo reificados enquanto mercadorias e espectadores perfeitos.

O totalitarismo foi descrito por Arendt como "[...] a dominação permanente de todos os indivíduos em toda e qualquer esfera da vida" (ARENDT, 1989, p. 375). Com isto, "[...] a diferença fundamental entre as ditaduras modernas e as tiranias do passado está no uso do terror não como meio de extermínio e amedrontamento dos oponentes, mas como instrumento corriqueiro para governar as massas perfeitamente obedientes" (ARENDT, 1989, p. 26).

O totalitarismo atual transcende o caráter político-estatal para dominar a cena do cotidiano dos sujeitos alienados e reificados. Despojados da livre iniciativa, apesar da falácia da liberdade ser "vendida" diariamente pelos telejornais, revistas e mídias sociais. 
$\mathrm{Na}$ falência dos instrumentos estatais de garantia do bem-estar social, falta de autonomia do Estado Nacional frente ao sistema capitalista e os limites da ação política, somente restará a barbárie.

As minorias sociais nem sequer existem para a sociedade fetichista e, consequentemente, as políticas sociais para estas populações também não são prioritárias. Mas, como inserir socialmente aqueles que a sociedade e as políticas sociais excluem?

Muito avançamos no campo das políticas públicas de saúde mental a fim de garantir os direitos humanos e que a assistência psiquiátrica não seja degradante ao se realizar em hospícios pelo país. Ao longo de 17 anos, desde a sanção da Lei 10.216 em 2001, que garante o direito à assistência das pessoas com transtornos mentais em serviços que visam substituir os manicômios, houve ampliação na cobertura dos Centros de Atenção Psicossocial (CAPS) Brasil afora.

Porém esta ampliação não veio, necessariamente, acompanhada pela quebra de preconceitos e estigma que impedem que as ações intersetoriais possam ser implementadas. Mesmo dentro do setor saúde, os doentes mentais enfrentam dificuldade de tratar de doenças que sejam do corpo. Suas necessidades de saúde não são atendidas plenamente.

Além dos serviços, ações políticas e sociais que visem à garantia de direitos civis e humanos destas pessoas também se tornam imperativas. A atenção a essas duas necessidades básicas, ou seja, saúde e autonomia não poderão ser alcançadas sem a existência de políticas públicas eficientes no acolhimento das demandas singulares dos cidadãos com transtornos mentais e abuso de drogas lícitas e ilícitas.

Porém temos assistido, a partir de 2016, um desmonte da política nacional de saúde mental com o retorno de grupos conservadores, ligados à indústria da loucura e à indústria farmacêutica. Assume a coordenação nacional de saúde mental médicos que, em nome da ciência e "baseado em evidências científicas", fomentam o financiamento de hospitais psiquiátricos, estimulam a abertura de leitos hospitalares especializados e a compra de aparelhos para realização de eletroconvulsoterapia, negando a evidência de que o tratamento comunitário, intersetorial e interdisciplinar é efetivo para redução de estigma e reinserção social. 
Já não precisamos de manicômios físicos porque vivemos o totalitarismo das imagens e do valor onde tudo que não seja rentável, tudo que não possa ser transformado em mercadoria, é naturalmente excluído da sociedade e considerado desnecessário e invisível.

Os profissionais da área de saúde mental lutam pelo resgate do poder contratual dos doentes mentais a fim de alcançar ganhos de autonomia para caminhar na vida, necessidades que, infelizmente, não dialogam com as necessidades do Capital².

E, assim, necessidades humanas básicas, direito à saúde e a autonomia dos doentes mentais estão ameaçados por notas técnicas e portarias de gabinete, sem um debate público exercido, na medida em que estão a ruir todos os esforços feitos pelos movimentos sociais reformistas nas últimas quatro décadas, respeitando-se a bandeira dos Direitos Humanos Fundamentais.

Os desafios atuais se ampliam.

\section{Referências}

AMARANTE, P. Reforma Psiquiátrica e Epistemologia. Cad. Bras. Saúde Mental, v.1 n.1, p.34-41, 2009.

ARENDT, H. Origens do Totalitarismo: antisemitismo, imperialismo, totalitarismo. Tradução: Roberto Raposo. Editora Companhia das Letras, 1989.

BAUMAN, Z. Vida Líquida. Tradução de Carlos Alberto Medeiros. Rio de Janeiro: Editora Zahar, 2007.

CALDAS DE ALMEIDA, J. M.; HORVITZ-LENNON, M. An overview of Mental Care Reforms in Latin America and Caribbean. Psychiatric Services, v. 61, n.3, p. 218-21, 2010.

CASTEL, R. A Ordem Psiquiátrica: idade de ouro do alienismo. Tradução de Maria Tereza da Costa Albuquerque. Rio de Janeiro: Graal, 1978.

2 O Ministério da Saúde emitiu uma Nota Técnica no. 11/2019 dia 04 de fevereiro de 2019 e a retirou de circulação dois dias depois após receber reação intensa de entidades envolvidas com direitos humanos e em defesa das pessoas com transtornos mental. A Nota tinha 32 páginas e além de incentivar a abertura e manutenção de leitos psiquiátricos, afirmava que os CAPS não são serviços substitutivos de saúde mental como são reconhecidos, dando a entender que a convivência entre CAPS e hospitais psiquiátricos seria a regra. Em alguns estados, hospitais antes fechados após auditorias realizadas em anos anteriores, passaram a solicitar recredenciamento ao SUS seguindo a fluxo da Nota Técnica hoje suspensa, ou melhor, em análise interna do Ministério da Saúde. 
DALLARI, S. G. O dirieto à saúde. Rev. Saúde públ.,v. 22, n.1, p. 57-63, 1988.

FOUCAULT, M. O Nascimento da Clínica. Tradução de Roberto Machado. Rio de Janeiro: Forense-Universitária, 1977.

FOUCAULT, M. Microfísica do Poder. 23.ed. São Paulo: Graal, 2007.

GOFFMAN, E. Estigma: notas sobre a manipulação da identidade deteriorada. 4.ed. Rio de Janeira: Editora Guanabara, 1988.

GOMES JÚNIOR, N. N.; PEREIRA, P. A. P. Necessidades do capital versus necessidades humanas no capitalismo contemporâneo: uma competição desigual. Argumentum, v. 5, n. 1, p. 50-63, 2013.

HAN, B. A Sociedade do Cansaço. Petrópolis: Editora Vozes. 2015.

HAN, B. Psicopolítica. Neoliberalismo e nuevas técnicas de poder. Tradução de Alfredo Bergués. Barcelona: Herder Editotial S. L., 2014.

KINOSHITA, R.T. Contratualidade e reabilitação psicossocial In: Pitta, A. M. F. Reabilitação psicossocial no Brasil. 3. ed. São Paulo: Hucitec, 2001. p. 55-59.

KURZ, R. Perdedores globais. In: KURZ, R. Os últimos combates. Petrópolis: Ed. Vozes, 1997. p. 135-141.

MÉSZARÓS, I. Para Além do Capital: Rumo a uma teoria de transição. São Paulo: Boitempo Editorial, 2002.

PEREIRA, P. A. P. A intersetorialidade das Políticas Sociais na perspectiva dialética. In: Monnerat. G. L.; ALMEIDA, N. L. T; SOUZA, R. G. A Intersetorialidade na Agenda das Políticas Sociais. Campinas: Papel Social, 2014. p. 23-39.

PITTA, A. Reabilitação Psicossocial no Brasil. São Paulo: Editora Hucitec, 2001.

SARACENO, B. Libertando identidades: da reabilitação psicossocial à cidadania possível. 2. ed. Rio de Janeiro: Te Corá/Instituto Franco Basaglia, $2001 a$.

SARACENO, B. Reabilitação Psicossocial :Uma estratégia para a passagem do milênio.In.:PITTA, A. Reabilitação Psicossocial no Brasil. São Paulo: Editora Hucitec, 2001b. p.13-18.

UZACÁTEQUI, R. G.; LEVAV, I. Reestruturação da assistência psiquiátrica: bases conceituais e caminhos para a sua implementação. Washington: Organização PanAmericana da Saúde, 1991.

WHO, World Health Organization. Quality-Rights tool kit to assess and improve quality and human rights in mental health and social care facilities. 2012. Disponivel em: http://www.who.int/mental health/policy/qualityrights/en/index.htmlJ. Acesso em: $30 \mathrm{dez}$. 2016. 
WHO, World Health Organization. Mental Health Action Plan 2013-2020. 2013. Disponível em: <http://apps.who.int/iris/bitstream/10665/89966/1/9789241506021_eng.pdf?ua=1>.

Acesso em: 30 dez. 2016.

WOLKMER. A. C. As Necessidades Humanas como Fonte Insurgente de Direitos

Fundamentais. Veredas do direito, v. 1, n. 3, p. 85-92, 2014.

\section{Dados das autoras}

Ana Raquel Santiago de Lima

Mestre em Políticas Sociais e Cidadania/Universidade Católica do Salvador (UCSAL), Departamento de Medicina de Lagarto (DMEL), Universidade Federal de Sergipe (UFS), anaraquel1306@gmail.com

Ana Maria Fernandes Pitta

Dra em Medicina Preventiva/Saúde Mental (USP), professora do PPG Políticas Sociais e Cidadania, UCSal, Presidente da Associação Brasileira de Saúde Mental; E-mail: ana.pitta@pro.ucsal.br 